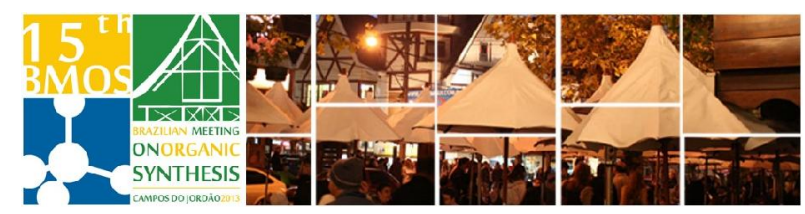

\title{
Synthesis of Diselenide Based Picolylamide Derivatives: Biologically Potential Compounds
}

\author{
Jamal Rafique ${ }^{1, *}(P G)$, Sumbal Saba ${ }^{1}$ (PG), Rômulo F. S. Canto ${ }^{1}$ (PG), Waseem \\ Hassan $^{2}$ (PG), João B. T. Rocha ${ }^{2}(P Q)$ and Antonio L. Braga ${ }^{1}(P Q)$ \\ ${ }^{1}$ LabSelen-Lab. de Síntese de Substâncias Bioativas de Selênio, UFSC, Florianópolis 88040-970, SC, Brazil \\ ${ }^{2}$ Dept. de Química, Centro de Ciências Naturais e Exatas, UFSM, Santa Maria 97105-900, RS, Brazil \\ *e-mail corresponding author. jamal.chm@gmail.com
}

Keywords: Picolylamide, diselenide, antioxidant

\section{INTRODUCTION}

Interest in synthetic organoselenium compounds has been growing since the 1970s, when many reports described the identification of various selenoproteins, which are involved in a wide number of physiological processes in mammals, such as antioxidant defense, thyroid hormone production and immune responses, ${ }^{1,2}$. There are many reports regarding the biological importance of diselenides having amide bond. The presence of amide bond in close proximity of selenium not only improves the biological activity but also improves the stability of the compound ${ }^{2,3}$.

Thus, according to our interest in bioactive organoselenium compounds ${ }^{4}$, herein, we describe the synthesis of diselenide based picolylamides 1 (Figure 1), as potentially bioactive molecules.

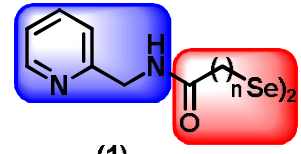

(1)

Figure 1. Diselenide based picolylamide

\section{RESULTS AND DISCUSSION}

Initially, aliphatic diselenides containing free carboxylic acid 2a-c were prepared, from the reaction of the corresponding bromo carboxylic acids with $\mathrm{Na}_{2} \mathrm{Se}_{2}$, generated in situ, from $\mathrm{NaBH}_{4}$ and selenium (Scheme 1).

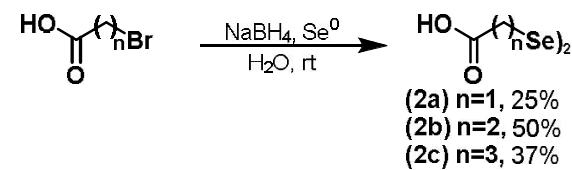

Scheme 1. Synthesis of aliphatic diselenides containing free carboxylic acid

The 2,2'-diselenobisbenzoic acids $\mathbf{2 d}$ was prepared through diazotization of anthranilic acid followed by reaction with $\mathrm{K}_{2} \mathrm{Se}_{2}$ (obtained by reaction of $\mathrm{KOH}$ with selenium) (Scheme 2).

In the following step, the amidation reaction was carried out, by reacting diselenides of $\mathbf{2 a - d}$ with picolylamine 3 using different coupling conditions.

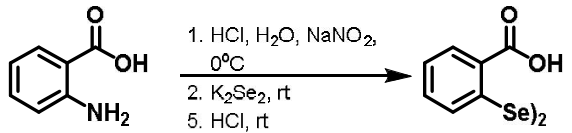

(2d) $91 \%$

Scheme 2. Synthesis of 2,2'-diselenobisbenzoic acids

Best results were achieved by using DCC-DMAP in anhyd. DCM, resulted the desired diselenides 1 in very good yield (Scheme 3 ).

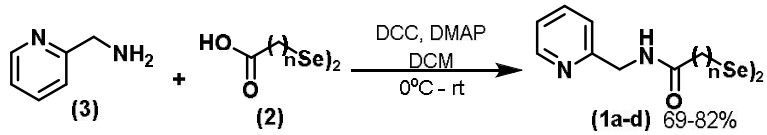

Scheme 3. Synthesis of seleno-picolylamides

Initial experiments shows that these diselenide 1a-d will be an excellent candidate to act as GPxmimic. For example, in case of 1c the time required to reduce the concentration of thiol to $50 \%$ was 17.4 min at $100 \mu \mathrm{M}$ concentration.

\section{CONCLUSION}

In the present study, a number of picolylamide containing diselenides 1a-d were synthesized through the coupling reaction of diselenides containing free carboxylic acid 2a-d with picolylamine 3. According to the initial results diselenide 1c can act as GPx-mimic, which reduce the concentration of thiol to $50 \%$ in $17.4 \mathrm{~min}$ at 100 $\mu \mathrm{M}$ concentration.. Moreover, the amides 1a-d will also be evaluated in other biological assays (in-vivo \& in-vitro)

\section{ACKNOWLEDGEMENTS}

CNPq, TWAS, UFSC, and INCT-Catálise

\section{REFERENCES}

1 Jacob, C.; Giles, G. I.; Giles, N. M. e Sies H., Angew. Chem. Int. Ed., 2003, 42, 4742

Braga, A. L. e Rafique, J. in Patai's Chemistry of Functional Groups), ed Z. Rappoport, John Wiley \& Sons, Ltd., Chichester, 2013, vol. 4.

${ }^{3}$ Mugesh, G.; du Mont, W.-W. e Sies, H. Chem. Rev. 2001, 101, 2125.

${ }^{4}$ Kawasoko, C. Y.; Foletto, P.; Rodrigues, O. E. D.; Dornelles, I.; Schwab, R. S. Braga, A. L. Org. Biomol. Chem. 2013,11, 5173. $15^{\text {th }}$ Brazilian Meeting on Organic Synthesis - 15 ${ }^{\text {th }}$ BMOS - November 10-13, 2013 - Campos do Jordão, Brazil 